\title{
ZENEA Y EL ROMANTICISMO CUBANO
}

\author{
POR \\ CINTIO VITIER \\ Centro de Estudios Martianos
}

Aunque en el campo de la crítica resultó con frecuencia - incluso por parte de sus protagonistas - frenado o ironizado ${ }^{1}$, y a pesar de sus inevitables fuentes e influencias europeas, el romanticismo poético cubano, desde Heredia y la Avellaneda hasta Zenea y Luisa Pérez de Zambrana, fue sin duda un vigoroso movimiento de independencia espiritual, con manifestaciones políticas mayores o menores, según los casos, aunque en el fondo siempre la implicación política profunda, y caracterizado por dos rasgos específicos: la autoctonía y el valor. Cuando decimos autoctonía no estamos pensando especial ni principalmente en las corrientes vernáculas, que fueron en general las menos significativas y perdurables, aunque propiciaran una figura de primer orden en su género, el arquetípico Cucalambé, hallador definitivo de la entonación campesina en la décima por él acuñada. Nos referimos sobre todo $-\mathrm{y}$ es el punto de confluencia de los dos autoctonismos en sus más altos logros- al sentimiento de rebeldía, independencia y libertad que venía de la tierra y el aire como elementos fundamentales de la inspiración histórica. No aludimos con esto al determinismo positivista de Taine y su teoría del «milieu» (aunque tal vez tendría que ser revisada mediante un replanteo más científico que el causante de su descrédito), sino al señalamiento martiano del «instinto que, como dote de la tierra, los llevó [a nuestros primeros patricios] a quebrantar su propia autoridad, antes que a perpetuarla» ${ }^{2}$, de tal modo que la tierra,

' Cf. Cintio Vitier, La crítica literaria y estética en el siglo XIX cubano (La Habana: Biblioteca Nacional José Martí, 1968-1974), t. I, pp. 29-35.

2 José Martí, Obras Completas (La Habana: Editora Nacional de Cuba, 1963-1973), t. 5, p. 145. Todas las citas de Martí provienen de esta edición, que en adelante se nombrará O. C. 
el «país», al pasar por la sensibilidad y la conciencia de los hombres, se nos iba convirtiendo en "patria»; o cuando nos dice que «el aire está lleno de almas» ${ }^{3}$ animismo que apunta no a una fantasía insustancial, sino a una autoctonía entrañable que ha saturado el paisaje indígena y convierte la respiración del aire libre en una metafórica y real ins-piración. Fue esa inspiración - - esa herediana respiración del «aire de luz» de la Isla- la que despertó en Martí, desde su niñez, según su memorable confidencia pública en el discurso de 1889 , «la pasión inextinguible por la libertad» ${ }^{4}$. Y cuando decimos valor, valentía, rasgo en apariencia ajeno a los «valores» poéticos, llamamos la atención, como lo hemos hecho en otras páginas, pero de otro modo, a la vinculación establecida también por Heredia entre la armoniosa hermosura del paisaje y la eticidad herida por la injusticia. La naturaleza interiorizada, que es lo que propiamente llamamos paisaje, adquiere en el «primogénito del romanticismo hispano», como llamara Manuel Pedro González a Heredia ${ }^{5}$, la calidad de una lección, de una inspiración en que lo estético y lo ético no son separables e iluminan la conciencia de la hombría poética. Esa iluminación, como esa hombría, no pueden ser meramente literarias. Por eso Heredia será un conspirador y un desterrado, completando así su imagen de poeta libertario, contra la que nada podrán —y por eso Martí lo justifica — sus nostalgias de moribundo ni sus desengaños honrados, nunca cobardes. «Mi verso al valiente agrada» ${ }^{6}$, dirá Martí, recogiendo en un plano ya exento de flaquezas y confusiones ese rasgo poético-vital de nuestro romanticismo fundador, sucesiva y cimeramente representado por Heredia y por Zenea.

En varios pasajes de Heredia — como el famoso «Era la tarde; su ligera brisa...», de «En el teocalli de Cholula», o en la primera estrofa de «A la estrella de Venus»- se prefigura el tono transido y crepuscular de Zenea, quien, a su vez, escribió cantos patrióticos de un antiespañolismo y una elocuencia que sólo pueden compararse con los análogos de Heredia. Pero sólo Heredia pudo escribir la oda al Niágara y sólo el autor de Cantos de la tarde pudo escribir «Fidelia». Con esta sencilla observación estamos deshaciendo un esquema (el romanticismo «exterior» de Heredia frente al «interior» de Zenea) y a la vez reafirmando la creciente interiorización de nuestro romanticismo, estructuralmente armado al principio con los recursos clásicos o neoclásicos de la oratoria lírica española, y finalmente librado, mediante la ayuda de Musset y Lamartine, al misterio desnudo

${ }^{3}$ O. C., t. 7, p. 407.

${ }^{4}$ O. C., t. 5, p. 165

${ }^{5}$ Cf. Manuel Pedro González, José María Heredia, primogénito del romanticismo hispano. Ensayo de rectificación histórica (México: El Colegio de México, 1955).

${ }^{6}$ O.C., t. 16, p. 72. 
de las emocionadas sensaciones, al temblor de la atmósfera y «la hora». Los préstamos franceses de Zenea, incluso cuando rozan lo literal, demuestran de nuevo que la intertextualidad constituye para el poeta $-\mathrm{y}$ sin duda mucho más para el poeta hispanoamericano - una paradójica materia prima. Su Musset no fue menos cubano que el Baudelaire de Casal: le bastó leerlo para asumirlo y transformarlo, sin tener siquiera que realizar esa «transcripción para flauta» que, según observara genialmente Lezama ${ }^{7}$, llevó a cabo con dos versos de Gallego: «a tardo paso soñoliento Arturo / en el mar de occidente se sepulta», modulándolo en una larga onda melódica («Baja Arturo al Occidente / bañado en púrpura regia...») mediante una cadencia de doce versos que, por otra parte, ejemplifica magistralmente la desespañolización del romance, o más bien, ese «no sé qué» del romance de Zenea, que tanto impresionó a Darío ${ }^{8}$. Tales apropiaciones y transmutaciones tienen un sentido político que, precisamente por menos obvio, nos pone de manifiesto la absoluta historicidad y politización de que se nutrió nuestro romanticismo. No se trata de evocar, una vez más, los textos patrióticos que todos recordamos, ni tampoco de olvidarlos, sino de verificar la marca profunda de la Colonia en los textos no aparentemente «patrióticos» ni «políticos» de Heredia, Plácido, Milanés, la Avellaneda, Mendive, Luaces, Luisa Pérez o Zenea. En el caso de este último, fuera de su explícita poesía civil, tan sinceramente iracunda contra la España colonial, dos dimensiones principales y complementarias de su más personal lirismo se nos imponen: la desierta intemperie marina y el penumbroso «interior», hogareño o erótico. Ejemplo inagotable de lo primero son las dos estrofas iniciales de «Recuerdo» («Cuando emigran las aves en bandadas...»); de lo segundo, el nocturno «Noche tempestuosa» («Murió la Luna; el ángel de las nieblas...») y los hechizantes versos dedicados a la

${ }^{7}$ Cf, Juan Clemente Zenea, Poesía, recopilación y prólogo de José Lezama Lima (La Habana: Instituto de Literatura y Lingüística, 1966), pp. 10-11. Todas las citas de Zenea provienen de esta edición. Lezama escribió también sobre Zenea la nota correspondiente en su Antología de la poesía cubana (La Habana: Consejo Nacional de Cultura, 1965), t. 3, pp. 191-200, y un largo estudio incluido en La cantidad hechizada (La Habana: Ed. Unión, 1970), pp. 259-328.

${ }^{8}$ «Cuando en la historia de sus libros hace un recuento de sus composiciones de Azul... dice que en "Primaveral", de El año lírico, cree haber dado "una nueva nota en la orquestación del romance con todo y contar con antecesores tan ilustres al respecto como Góngora y el cubano Zenea", y no hay que olvidar que ese romance es de los veinte años de Darío. Este vuelve a unir a creadores tan disímiles en su comentario al libro Arias tristes, de Juan Ramón Jiménez, cuando señala que determinado romance "suena a la música del divino Góngora; y para nosotros, los americanos, a la música de un rimador de encantos y tristezas, de un adorable orfeo cubano, ha tiempo desaparecido. Esas notas las hemos oído en las cuerdas que acariciaba la mano de Zenea". Cf. Angel Augier, Cuba y Rubén Dario (La Habana: Instituto de Literatura y Lingüística, 1968), p. 8. 
memoria de Adah Menken («Lanzaba un rayo tenue y azulado / la lámpara encubierta con un velo...»). Ambas dimensiones son inseparables de una sensibilidad conformada por la vivencia del destierro, es decir, por una situación político-existencial que llega hasta las raíces del ser. A partir de ese descentrado centro, en la poesía de Zenea el afuera es una abertura inconmensurable, desierta y resonante, una desolada orfandad llena de ecos, mientras el adentro es el refugio de la amante o de la esposa, rodeado por la nieve o por la lluvia, amenazado siempre, en su dicha tan intensa como frágil, por la angustia. La historia, es decir, la injusticia y la lucha todavía impotente contra ella, es el dato inescapable, dominante, configurador, en el más profundo sentido, de esta poesía.

Dicho en otras palabras: nuestro romanticismo, culminante en Zenea, coincidente a través de dos generaciones con la toma de conciencia de la patria esclavizada y del "pecado original» (según la sentencia de José de la Luz) que sustentaba y deformaba a la sociedad cubana, encarnó y expresó esa situación histórica, política y social, en todos los planos: desde la indignada denuncia ética y patriótica, pasando por las búsquedas de una identidad costumbrista y vernácula (incluso, fallidamente, indigenista), hasta los niveles más hondos e irradiantes de la intimidad y de la trascendencia. Ningún poema fue tan capaz de recoger estos últimos registros, sin perder nunca de vista la estrella revolucionaria que los imantaba, como el titulado «En días de esclavitud», verdadera summa del más acendrado y militante romanticismo cubano. La fragmentación a que lo han sometido las antologías quizá ha impedido calibrar la riqueza de estos cuatro cantos enlazados por el dolor del destierro, la vergüenza de la esclavitud y el ansia de libertad. Se dedica el primero a las vivencias del que parte de la patria, como quien se desgarra, por no ser cómplice de su deshonra. Si la Avellaneda, al despedirse de la que consideraba «patria feliz», cierra su inolvidable soneto tan afortunadamente: «El buque, estremecido, / las olas corta y silencioso vuela», todo el drama que embarga a Zenea se concentra en un solo verso: «Y el opreso vapor se escapa y grita»: opresión y grito que son los de su alma, ya identificada en «Recuerdo» con el grito de las aves migratorias. El espacio poético que en «Al partir» ocupaba «la chusma diligente» lo ocupan aquí «los amigos angustiados» que se abrazan; la simple brisa que acudía de la «zona ardiente» para henchir las velas se torna aquí «la brisa gemidora». Todo es dolor en esta despedida, que pronto empieza a captar las sensaciones crepusculares del alejamiento, tan preferidas por Zenea: «los ecos tristes de la tarde», «las tintas melancólicas y bellas», "la incierta raya / que dibujan las costas y los montes», hasta que, hundidas las palmas en el azul que inunda al horizonte, sobre la inmensa soledad marina se enfrentan el sol poniente y la luna en ascenso: 
«un globo de oro y sangre en el ocaso / y un globo de alabastro en el oriente», versos que Casal recibiría con una reverencia. Entonces surgen las preguntas, resumibles en una sola: ¿Por qué el destierro? La respuesta - la misma desde Heredia hasta Zenea- es tan sencilla como concluyente: «Porque buscamos libertad». Si aquí terminara el poema, sería, no más, otra bella formulación del separatismo romántico. Pero Zenea, como ya lo apuntamos, ahondó en la situación del desterrado hasta sus resonancias más universales y trascendentes. En la exclamativa irrupción que inicia el segundo canto, uno de los momentos más altos de toda nuestra poesía, el desterrado ya es «el hombre» mismo, en su desvalimiento, errancia y desamparo existenciales, por lo que se justifica el tono súbitamente bíblico de este memorable arranque:

\author{
¡Señor! ¡Señor! jel pájaro perdido \\ Puede hallar en los bosques el sustento. \\ En cualquier árbol fabricar su nido \\ $\mathrm{Y}$ a cualquier hora atravesar el viento! \\ ¡Y el hombre, el dueño que a la tierra envías \\ Armado para entrar en la contienda. \\ No sabe al despertar todos los días \\ En qué desierto plantará su tienda!
}

El éxodo de los cubanos del XIX parece equipararse al éxodo de los israelitas, según se confirma al final de este canto, donde leemos: «Con mi país de promisión no acierto»; pero, a partir de la tercera estrofa, el poeta habla en primera persona, y quizá por ello sus símiles tienen la exquisita y familiar delicadeza de sus mejores intimidades líricas. El juego del cisne con «el brillo de la luna / nadando entre el reflejo de la tarde», versos que Darío seguramente acarició; el perfume de la azucena, que se esparce «sin lastimar su cáliz delicado» mientras el corazón del poeta se despedaza al descubrir su pena, versos que nos recuerdan los del místico del «pecho del amor muy lastimado», conducen de lo genérico a lo personal: «¿Y quién soy yo?» Después de intuir y expresar el destierro esencial de la criatura humana caída por el «pecado original» (que no lo era sólo de la sociedad cubana, sino de toda la humanidad: el pecado de soberbia y de injusticia, causante de todas las formas de esclavitud), tiene Zenea el acierto de volver, sin dejar de sentirse «en presencia de Dios y lo infinito», a su específica situación histórica y biográfica, pues la poesía no resiste mucho tiempo lo genérico y abstracto, como lo demuestra el que necesite hacerlo valer mediante símiles concretos (el pájaro perdido, el cisne, la azucena), artificio en que Dante fue maestro. No deja nuestro «poeta 
vagabundo» de evocar al genio florentino en su condición de desterrado político muerto en tierra extranjera, destino que pudo ser el suyo, como el de Heredia y tantos otros. Su pena de no tener patria digna le hace pedir en este canto «otra patria, otro siglo y otros hombres», y proclamar su añoranza de las repúblicas clásicas: «Mis tiempos son los de la antigua Roma, / y mis hermanos con la Grecia han muerto», utopía retrospectiva cuyo ingenuo valor simbólico es lo único capaz de amparar $-\mathrm{y}$, en efecto, lo ampara y equilibra - el candor de su rotundidad retórica. Mas retomemos la pregunta: «¿Y quién soy yo?» ¿El hijo errante de un Dios incomprensible, de un pueblo deshonrado, de unas virtudes perdidas? ¿Y nada más? Sí, mucho más. En el canto tercero no señorea la angustia, sino la libertad, aprendida desde la niñez en la contemplación del mar: «¡Primer amor de mis primeros años»; adorada desde la adolescencia: «Tu voz solemne / como la voz de una mujer querida / con músicas sonoras / llenó las soledades de mi vida [...] y fue a vibrar en lo mejor del alma.» $\mathrm{Al}$ adentrarse en la plenitud solitaria y libre del océano - «Homme libre: toujours tu cheriras la mer», había exclamado el todavía romántico Baudelaire-, Zenea encuentra la más amplia respiración de su verso y se complace imaginando la salvaje soledad del mar precolombino, sólo turbada en su «profundo olvido» por la queja de «los alciones tristes» o por «el grito aterrador de las gaviotas». Es a ese mar-imagen de la absoluta libertad - y más aún: de lo desconocido, de lo intocado, de lo virgen-al que pregunta por qué no hundió las naves españolas, evitando así la «infausta servidumbre» y el holocausto de indios, negros, mujeres, niños: «ide aqueila desgraciada muchedumbre / que pasto fue de la indomable fiera!» Vuelven en este punto los encarnizados acentos antiespañoles de su poesía civil, la menos valiosa literariamente, si bien no la menos sincera y significativa; pero lo decisivo en este canto es la revelación de que «aquí, sobre el piélago salado / el hombre es dueño de su ser y es hombre»; y de que por lo mismo «aquí en el seno / de la grandeza suma es donde mora / el monarca del cielo y de la tierra». Ya el hijo no se siente abandonado por su Padre en una desolada errancia llena de angustiosos ecos, en un enigmático destierro interminable. El herediano «Señor de los aires», el Señor de la Libertad y la Justicia, físicamente revelado por el fragor de la tempestad en la intemperie marina, es el Señor de los Ejércitos. La lógica del poema, pues, en afinada consonancia con la dialéctica emocional del poeta, exige que el último canto sea el de la congoja por «la patria herida», el de la indignación por los vicios coloniales y la ausencia de «ínclitos varones»: «las siervas maridando con esclavos / siervos y esclavos nada más procrean!»; el de la invocación a los ríos tutelares, el Tínima y el Cauto, para que unidos a toda la naturaleza insular provoquen la catástrofe purificadora; el canto, en fin, 
anunciador - con versos que parecen también anunciar los finales de $A b$ dala - de la insurrección revolucionaria, que empezaría pocos años después, y del jubiloso triunfo del pueblo, que casi un siglo más tarde se cumpliría: « $i Y$ en médio de los himnos de la guerra / al fin el pueblo vencedor saluda / el pendón de la estrella solitaria!»

Los más originales aportes de Zenea a la lírica cubana - la poesía vagarosa del bosque, los acentos elegíacos, los tonos crepusculares, sus visiones idílicas, alegóricas o impresionistas de la mujer, su intensa captación de los «interiores» en contraste con su apertura a la intemperie marina solitaria, sus ocasionales momentos premartianos y precasalianos--, unidos al hecho innegable de la menor calidad literaria de la mayoría de sus versos políticos, como «Dieciséis de agosto de 1851 en La Habana», «En el aniversario del General López» o «El filibustero», obstaculizaron la valoración integral de «En días de esclavitud», único poema en que las que podemos llamar sus dos inspiraciones confluyen. Esta parcialización o esquematización de un Zenea perennemente elegíaco, vaporoso y pesimista, obstaculizó también, desde luego, la comprensión integral del autor de Cantos de la tarde como poeta y como patriota, condición esta última que empezó a cuestionarse gravemente desde su último viaje a Cuba en 1870. Por esta fecha Zenea era ya una de las más connotadas figuras de la intelectualidad separatista cubana, perteneciente a una generación poética - la de El laúd del desterrado, Nueva York, 1858 - marcada por el bárbaro espectáculo de la ejecución de Narciso López y la matanza de sus expedicionarios el 16 de agosto de 1851: generación tan inevitable como ingenuamente contagiada de tendencias anexionistas. Colaborador de $L a$ Voz del Pueblo, de Eduardo Facciolo, lo que provocó su primer destierro, las virulentas campañas separatistas que llevó a cabo en la prensa revolucionaria de Nueva Orleáns y Nueva York, así como su desafiante actitud personal frente a las autoridades españolas, le valieron ser condenado a muerte en 1853. Vuelto a Cuba gracias a una amnistía general, su intensa actividad literaria, que incluyó muy valiosas incursiones en la crítica, culminó con la dirección de la Revista Habanera, fundada en 1861 y clausurada por el capitán general Domingo Dulce a principios de 1863. De nuevo autodesterrado en 1865, después de una ruinosa estancia en Nueva York, invitado por su amigo Pedro Santacilia, yerno y secretario del presidente Juárez, se trasladó a la capital de México, donde era director del Diario Oficial y preparaba una edición crítica de las obras de Heredia cuando estalló en Cuba la insurrección encabezada por su conterráneo bayamés Carlos Manuel de Céspedes. Tan pronto conoció este suceso, abandonando sin vacilaciones la estabilidad económica y familiar por primera vez disfrutada, volvió de inmediato a Nueva York para enrolarse en 
dos sucesivas expediciones a Cuba, la del «Lillian» y la del «Catherine Whiting», ambas fracasadas. Ganándose penosamente la vida como traductor y profesor de inglés y francés, reanuda sus campañas periodísticas en La Revolución, órgano de la Junta Revolucionaria presidida por Miguel Aldama, dirigido entonces por Enrique Piñeyro, y se caracteriza como un acérrimo enemigo del general Manuel de Quesada, cuyo arribo a Nueva York en marzo de 1870 polarizó las ya divididas fuerzas de la emigración en dos bandos irreconciliables: aldamistas y quesadistas. Solidarizándose con Piñeyro, al ser éste sustituido por Rafael María Merchán, Zenea salió de La Revolución en septiembre de 1870, y el 3 de noviembre del mismo año emprendió el mencionado viaje para entrevistarse con Carlos Manuel de Céspedes, viaje a la vez clandestino y supuestamente amparado por un salvoconducto español, que desató contra él las acusaciones de traición tanto de quesadistas como de aldamistas, finalizó con su fusilamiento en la fortaleza de La Cabaña el 25 de agosto de 1871.

Una poesía así, de pura alma en vilo, unida a una conducta irreprochable, de tenaz militancia revolucionaria, ¿pudo haber sido la de un traidor en potencia? Nunca lo creímos, en primer término por razones poéticas. La moralidad puede fingirse o quebrarse; el valor no es atributo exclusivo de los héroes, ni siquiera de las personas honradas; pero la transparencia de la palabra poética es siempre infalible, incluso implacable. Zenea escribió sus últimos versos, durante los ocho meses que pasó incomunicado en una bartolina de La Cabaña, frente a la inminencia de la muerte. Esos versos — póstumamente publicados por Piñeyro bajo el título de Diario de un mártir - transparentan la absoluta limpidez de su conciencia. A los que tienen de la poesía una idea ornamental, a los que son incapaces de distinguir sus grados de autenticidad, este argumento les resulta inadmisible. Fue, sin embargo, el principal que esgrimió Martí cuando el 8 de diciembre de 1894, en Patria, evocando los «días de muerte» del poeta, recordó aquellos «versos de augusta serenidad, donde no halla quien sabe de almas una sola voz de confusión o remordimiento» ${ }^{9}$. No faltará, de todos modos, quien tilde este juicio de sentimental, poco serio y prescindible, no obstante provenir del fundador del Partido Revolucionario Cubano, que aquel mismo día estaba firmando la Orden de Alzamiento para reiniciar la guerra de liberación en Cuba; y de hecho el juicio de Martí sobre Zenea, madurado a través de más de veinte años, no fue ni siquiera tenido en cuenta por los fiscales póstumos del autor de el Diario de un mártir. En vista, pues, de que son tantos, o tan tenaces, los que necesitan las llamadas «pruebas objetivas», estudié minuciosamente la bibliografía

${ }^{9} \overline{O . C ., \mathrm{t}}$ 5, p. 456. 
de los acusadores ${ }^{10}$, lo que me llevó a un análisis del proceso de Zenea tal como fue traducido del inglés por Carlos Loveira y por Antonio L. Valverde, y a un cotejo de esas versiones con una copia del proceso original en español, donada a la Biblioteca de Casa de las Américas por el investigador Raúl Rodríguez La O. También me ayudó notablemente en esta tarea, con nuevos aportes documentales, Dionisio Poey Baró, mi compañero en el Centro de Estudios Martianos. Sobra decir que en todo momento tuve a la vista el libro de Enrique Piñeyro Vida y escritos de Juan Clemente Zenea (1901), y que me vi obligado a realizar una lectura hermenéutica de la correspondencia de Carlos Manuel de Céspedes relativa a Zenea, así como una dilucidación a fondo de las diversas manifestaciones de Martí directa o indirectamente referidas a la figura y la conducta de nuestro poeta. El resultado de todo este trabajo fueron tres conferencias y un libro titulado Rescate de Zenea, entregado a la Unión de Escritores y Artistas de Cuba para su publicación. En él comprobará el lector, con una abundancia de datos, pormenores y argumentos que en estas páginas no podemos permitirnos, cómo ni uno solo de los cargos acumulados por los cubanos contra Zenea, y mucho menos los que él mismo utilizó como coartadas fallidas (si hemos de dar crédito en esto a los siempre sospechosos legajos españoles), se mantiene en pie ante una crítica objetiva y coherente. Ahora podemos asegurar que no hay absolutamente ninguna prueba de que Zenea haya actuado, ni por dinero ni por convicción, al servicio de la causa de $\mathrm{Es}_{1}$ )aña, que tanto odió toda su vida, ni que haya intentado engañar nada más que a dos personas, que eran dos enemigos: el periodista español Enrique Tabares y el embajador de España en Washington Mauricio López Roberts. El conde de Valmaseda, su verdugo, lo comprendió con entera claridad. En el polo opuesto, José Martí sentenció que su error, nunca su traición, fue ocasionado por «el deseo de sacar con decoro de la derrota a la patria que creía vencida» ${ }^{11}$. La única víctima de ese error fue él mismo.

El desastroso estado de la emigración y el creciente deterioro de las relaciones del presidente Céspedes con la Cámara habían convencido a

\footnotetext{
${ }^{10}$ Las principales acusaciones contra Zenea se hallan en el anatema de la Liga Hijas de Cuba, encabezada por Emilia Casanova de Villaverde, y en el folleto redactado por José Antonio Echeverría en defensa de la Junta Revolucionaria presidida por Miguel Aldama, respectivamente aparecidos en Nueva York el 5 y el 10 de febrero de 1871; en parte de la correspondencia de Carlos Manuel de Céspedes; en el libro de Carlos Manuel de Céspedes y Quesada sobre su padre (París, 1895); en la conferencia de Roque E. Garrigó publicada por la revista Cuba Contemporánea (n. 165-166, 1926); en el libro de Antonio L. Valverde Juan Clemente Zenea; su proceso de 1871 (La Habana: El Siglo XX, 1927), y en el ensayo de Sergio Chaple «Para una comprensión mejor de Zenea», aparecido en el Anuario $L / L$, n. 7-8, 1976-1977.

"O.C., t. 5, p. 456.
} 
Zenea de que la guerra iba al fracaso. En ambos factores consideraba funesta la actuación del general Manuel de Quesada ${ }^{12}$. La equivocación de Zenea consistió en creer que, en 1870 , la guerra ya estaba abocada al desastre, y que su continuación sólo podía acarrear calamidades y el descrédito total de la causa cubana. Su inmadurez política le impidió comprender que, como observara Martí en su artículo sobre Nicolás Azcárate, la nacionalidad cubana tuvo que ser «en los comienzos fea y revuelta, como las entrañas y las raíces», y que si «cayó en barbecho la revolución» fue sólo «por causas transitorias y de resultas sanas, que la crítica ligera pudo tener por definitivas y mortales» ${ }^{13}$. Ciertamente, los años de guerra que faltaban resultaron fundamentales para la consolidación de la nacionalidad y de jefes de extracción popular como los generales Gómez y Maceo, que asegurarían la continuidad de la Revolución. Obcecado Zenea en su error y en su impaciencia, pero a la vez inseguro acerca de la verdadera situación del campo insurrecto, después de haber intentado llevar armas infiltrándose en Cuba con una embarcación rápida que le fue negada por la Junta Central Republicana, y de enviar a Céspedes un mensaje lleno de inquietudes y recomendaciones que fue interceptado, su carácter compulsivo y temerario lo llevó a «autorreclutarse» como fingido espía asalariado de España para lograr de inmediato ir a Cuba, hablar con Céspedes, obtener información directa y servir de correo, contando en caso necesario con una garantía mayor que la que podía ofrecer un simple salvoconducto frente al odio jurado de los Voluntarios. Ese odio era especialmente temible para él, ya que también haría el viaje como enviado extraoficial de Nicolás Azcárate, aunque, según éste declaró, «sin romper sus compromisos con los separatistas cubanos» ${ }^{14}$. Azcárate era el promotor de una misión pacificadora respaldada por el ministro de Ultramar Segismundo Moret, misión en la que llegó a proponer a los miembros de la Junta Revolucionaria en Nueva York, a cambio de la capitulación, no sólo una amnistía general, un gobierno autonómico y el desmantelamiento del Cuerpo de Voluntarios, sino incluso la abolición inmediata de la esclavitud: es decir -fueran o no sinceras y factibles estas promesas-, mucho más de lo que se logró con

${ }^{12}$ El mismo criterio, despojado de ojerizas personales, sustentan en nuestros días los historiadores Fernando Portuondo y Hortensia Pichardo, principales especialistas en la figura de Carlos Manuel de Céspedes. Cf. el prólogo de su compilación de los Escritos de Céspedes (La Habana: Ciencias Sociales, 1982), t. I, pp. 68-69.

${ }^{13}$ O. C. t t. 4, pp. 473-476. Nicolás Azcárate fue el único reformista a quien Martí respetó y quiso, no obstante sus irreductibles discrepancias.

${ }^{14}$ Cf. el artículo de Azcárate «Una exigencia de honor», publicado en La Constitución, de Madrid, el 18 de septiembre de 1871 , y reproducido en el mencionado libro de Piñeyro, pp. 271-277. 
el Pacto del Zanjón en 1878. La conducta de Zenea en el campamento de Céspedes fue irreprochable, según consta y se reitera durante seis meses en la correspondencia del presidente, quien al regreso le confió la custodia de su esposa, Ana de Quesada, cuatro mil pesos y una importante documentación, incluyendo la respuesta negativa a las proposiciones de Azcárate. Al ser apresado con parte de su comitiva, sin que de nada valiera el salvoconducto, Zenea se negó a revelar el sitio del campamento de Céspedes, y durante los ocho meses que duró su proceso y confinamiento no delató nada ni a nadie. Entre tanto, los odios mutuos de quesadistas y aldamistas lo convirtieron en víctima expiatoria, pero Céspedes sólo cambió su opinión, de modo brusco y radical, después de recibir varias cartas de su esposa (ya a salvo en Nueva York) en julio de 1871. Aunque estas cartas no se conservan, por los comentarios que suscitaron en Céspedes es indudable que el dato nuevo y decisivo fue el «punado de oro» por el que supuestamente se vendió Zenea. Al encontrar en el Archivo Histórico de Madrid la cuenta del dinero entregado por la Legación de España en Washington a varias personas involucradas en la «misión Azcárate» (dando por segura, lo que no es obligatorio, la veracidad de ese papel), el investigador Paul Estrade ha permitido reducir a sus probables límites la cantidad, «de toda evidencia inferior a los dos mil y pico pesos (oro)» ${ }^{15}$, entregada a Zenea para los gastos de un viaje en que tuvo que trasladarse de Nueva York a Nassau, vivir allí varios días y fletar a sus expensas una goleta para llegar a las costas de Cuba, con las consiguientes generosas regalías que una aventura tan arriesgada, y el compromiso de volver a recogerlo en lugar y plazo fijos, tuvieron que implicar. Lo que no sabemos es la cantidad que fíguraría en las cartas de Ana de Quesada, cuya patente animadversión contra Zenea por la de éste contra su hermano la hacía proclive a dar crédito a las peores especies contra el poeta, si bien algún tiempo después escribiría a su esposo: «Dios quiera que al pobre del comisionado [Aguilera] no le den un salvoconducto español como al pobre Zenea (q.e.p.d.)» ${ }^{16}$.

En paz podía descansar, en efecto, después de tanto martirio, porque en paz con su conciencia había vivido y muerto, como un valiente, quien fuera el último de los grandes líricos del romanticismo cubano, el concentrador de sus más finas, hondas y perdurables esencias.

${ }^{15}$ Cf. Paul Estrade: «El punado de oro de la traición de Zenea», en Revista de la Biblioteca Nacional José Martí, enero-abril 1978, pp. 93-100.

${ }^{16}$ Carta de 18 de abril de 1873, en Escritos de Carlos Manuel de Céspedes, ed. cit., t. III, pp. $237-238$ 
